\title{
Mechanism of action of intravenous immunoglobulin in immune-mediated cytopenias
}

\author{
H I ATRAH, R J L DAVIDSON \\ From the Department of Haematology, Aberdeen Royal Infirmary, Foresterhill, Aberdeen, Scotland
}

The value of immunoglobulin (Ig) for replacement therapy in patients with primary antibody deficiency was realised in the early 1950's and its immunosuppressive effects a decade later. ${ }^{1}$ Initially maternal source Ig preparations were used to enhance cadaveric renal graft survival ${ }^{2}$ and plasma, as a source of Ig, was used to treat idiopathic thrombocytopenic purpura. ${ }^{34}$ As an immunosuppressive agent, Ig did not, however, gain wide application until 1981; this followed a chance observation by Imbach et al, ${ }^{5}$ who in the course of intravenous immunoglobulin treatment of children with hypogammaglobulinaemia noted that the platelet count of two such children with coincidental idiopathic thrombocytopenic purpura suddenly improved after the infusion of intravenous Ig. This observation was soon confirmed both in children ${ }^{67}$ and adults ${ }^{8-10}$ with acute and chronic forms of idiopathic thrombocytopenic purpura. It has been subsequently and amply shown that the platelet response is more favourable in the acute form of the disease $^{1112}$ where it may, however, be difficult to distinguish sustained increases in platelet count from spontaneous remissions. Prolonged and unmaintained remission after intravenous Ig treatment is rare in chronic idiopathic thrombocytopenic purpura, but most such patients obtain a transient rise in the platelet count (for a few weeks), often ensuring adequate time and haemostasis for splenectomy or other essential surgery.

Apart from preoperative preparation, intravenous Ig may also be successful in deferring or avoiding splenectomy while booster infusions may sustain remission in patients in whom steroids are contraindicated. In recent years the potential therapeutic value of intravenous Ig has been extended to a broad spectrum of disorders, particularly those with a confir- med or suspected autoimmune aetiology including other blood cytopenias and diseases affecting the nervous, cardiovascular, endocrine, alimentary and other systems. The treatment protocols and clinical results are detailed in recent reviews. ${ }^{1314}$

Despite this relatively long background of intensive research and clinical application the mechanism underlying the immunomodulatory effect of intravenous Ig has tantalisingly eluded a unified and universally acceptable explanation. This deficiency may result from several factors: (i) intravenous Ig may have more than one mode of action; (ii) subtle variations in the constituents of different intravenous Ig preparations or batches may lead to differences in therapeutic activity, potency, and efficacy; and (iii) the disease being treated, immune based thrombocytopenia although superficially, a single clinical entity is more likely to be a syndrome of covert and variable pathenogenesis. Our prime objective in this article is to review critically and evaluate the bewildering number of explanatory mechanisms which have been proposed to date.

\section{Reticuloendothelial system blockade}

After intravenous Ig treatment the clearance of autologous anti- $R h(D)$ sensitised radiolabelled red cells is impaired for about one month consistent with transient interference of reticuloendothelial system macrophage $F c \gamma R$ (the receptor for Fc portion of IgG) function. ${ }^{915}$ Because the same receptor is responsible for the elimination of antibody-coated platelets, the rise in platelet count after intravenous Ig treatment has been similarly attributed to inhibition of $F c \gamma R$ function. It is generally agreed that the immediate rise in platelet count effected by treatment results from reticuloendothelial system blockade, but the actual mechanism of the blockade itself remains controversial and unresolved. It has been suggested that the following five main mechanisms may account for the blockade. 
1 REVERSIBLE BINDING OF THE FC PORTION OF MONOMERIC IgG TO RETICULOENDOTHELIAL SYSTEM MACROPHAGE Fc $\gamma R^{16}$

High dose intravenous Ig treatment leads to about a threefold increase in serum IgG and theoretically the number of $F \mathrm{c} \gamma \mathrm{R}$ reversibly occupied by $\mathrm{Ig}$ monomers. Consequently, the number of receptor sites available for binding the Fc portions of platelet-associated IgG (PA IgG) is reduced. This hypothesis is supported by the increase in IgG detected within monocytes after intravenous Ig treatment, presumably via internalisation of the receptor with its bound IgG. ${ }^{17}$

2 IRREVERSIBLE BINDING OF THE Fc PORTIONS OF IgG AGGREGATES TO RETICULOENDOTHELIAL SYSTEM MACROPHAGE Fc $\gamma \mathbf{R}^{18}$

After the irreversible binding IgG aggregates are readily phagocytosed because of multipoint attachment with internalisation and loss of FcyR expression. ${ }^{16}$ Intravenous Ig contains only small quantities of IgG aggregates ${ }^{19}$ but by this mechanism may contribute to the reticuloendothelial system blockade. ${ }^{20}$

\section{ANTIMICROBIAL ANTIBODIES}

Intravenous Ig may contain antimicrobial antibodies which interact specifically (via their Fab portions) with persistent microbial antigens to form immune complexes. ${ }^{21}$ The latter in turn are phagocytosed in a manner similar to that of IgG aggregates with resulting reticuloendothelial system blockade. Elimination of the infection itself may also normalise the platelet count.

\section{BLOOD GROUP ANTIBODIES}

The presence of specific blood group antibodies in intravenous Ig may cause low grade haemolysis or phagocytosis of antibody-coated red cells. ${ }^{22}$ Consequently, the rate of removal of antibody-coated platelets may be reduced because of the limited capacity of the reticuloendothelial system. Proponents of this mechanism cite the accompanying absence or reduction in haptoglobins following intravenous Ig as substantive evidence although such haptoglobin changes have not been recorded in all studies. ${ }^{23} 24$

Furthermore, patients with Evan's syndrome may have clinically important immune destruction of red cells by the reticuloendothelial system without improvement in their immune thrombocytopenia. ${ }^{25}$ If this hypothesis is valid one might also anticipate that patients belonging to blood group $\boldsymbol{O}$ would be less likely to respond to intravenous $\mathrm{Ig},{ }^{26}$ but in one large study no association between patient response rate and blood group was established. ${ }^{27}$ Finally, a strong counterargument to this hypothesis is that intravenous Ig has a beneficial therapeutic effect in autoimmune haemolytic anaemia. ${ }^{14}$

\section{ANTI-Fc $\gamma$ R ANTIBODIES}

The presence of specific anti-Fc $\gamma R$ antibody in intravenous $\mathrm{Ig}$ causes reticuloendothelial system blockade (as detailed below).

It must be emphasised that although the reticuloendothelial system blockade theory is, in the main, accepted as the basis for the immediate platelet response, it by no means accounts for all the well founded observations and experimental data relating to intravenous Ig treatment. The most cogent arguments against the theory include the following: the reticuloendothelial system blockade is transient and limited to about four weeks' duration ${ }^{915}$ whereas the therapeutic effect may last in some patients for several months; although intravenous Ig may have achieved reticuloendothelial system blockade in some patients, there may be little or no accompanying platelet response ${ }^{28}$ and vice versa ${ }^{29}$; if reticuloendothelial system blockade is regarded as a percentage of the initial clearance all patients seem to have an identical pattern of immune particle clearance but the changes in platelet count are variable and show no constant relation with the corresponding reticuloendothelial system changes ${ }^{28}$; each of the hypotheses (1-4) hinges on the presence of intact (unmodified) IgG molecules with functional Fc portions, yet this apparent and structural prerequisite is at variance with the ability of intravenous Ig consisting of only or mainly Fab portions (modified IgG) to elicit responses comparable with those of unmodified preparations. $^{12}$ 30-32

From the evidence thus far presented it must be concluded that reticuloendothelial system blockade not only fails to account for the long term therapeutic responses of intravenous Ig but additionally fails to concur with certain well authenticated features of the more immediate responses. ${ }^{25}$ Not unexpectedly, several other mechanisms have therefore been advanced which attempt to elucidate the immediate platelet response. These mechanisms include:

\section{Inactivation (or neutralisation) of platelet antibodies by intravenous Ig}

This hypothesis emanated from the work of Sultan and coworkers, ${ }^{33}$ which showed that intravenous Ig contained anti-idiotype antibodies for the idiotypes of factor VIII autoantibodies. They speculated that intravenous $\mathrm{Ig}$ may similarly contain anti-idiotype antibodies to other antibodies, including platelet autoantibodies, and that its therapeutic efficacy in some autoimmune diseases may depend on such idiotypic/anti-idiotypic interactions.

Protection of platelet or megakaryocytes, or both, from platelet antiluodies

The proposition is that this protection may be afforded 
by non-specific attachment of the Fab or Fc portions of IgG in intravenous Ig to platelets or megakaryocytes, or both. Such a mechanism would thereby effectively eliminate or reduce any specific reaction between platelet antibodies and their target. ${ }^{34}$ The inhibitory effects of monomeric intravenous Ig on platelet activation by polymeric IgG is often quoted as supporting evidence for this mechanism, but the validity of such an assumption must be questioned because specific anti-platelet antibody was not used in the original experimental model. ${ }^{35}$ On the other hand, when normal platelets are incubated with platelet antibodies, no important difference is detected in the amount of platelet-associated IgG bound to untreated platelets and those treated with intravenous Ig. ${ }^{36}$ This finding confirmed by others both in vivo ${ }^{37}$ and in vitro $^{38}$ indicates that intravenous Ig is unlikely to exert any protective role via this suggested mechanism.

\section{Elimination of infection}

(see reticuloendothelial system blockade, point 3)

\section{Modulation of the Fc $\gamma R$}

Intravenous Ig treatment is associated with a decrease in the affinity of human monocyte $F c \gamma R$ for the $F c$ portion of rabbit IgG coating sheep red cells. ${ }^{17}$ Although observed under highly artificial and experimental conditions, this finding was attributed to a qualitative rather than a quantitative change in the Fc $\gamma R$. No such change was observed, however, in a subsequent study in which only human components were used. ${ }^{25}$

\section{Suppression of natural killer cell activity}

The activity of natural killer cells is increased in idiopathic thrombocytopenic purpura, autoimmune neutropenia, and some other autoimmune disorders ${ }^{39}$ and may be lytic in the presence of platelet or neutrophil antibodies. Intravenous $\mathrm{Ig}$ diminishes natural killer activity of lymphocytes of healthy donors in vitro in a dose-dependent pattern, ${ }^{39}{ }^{40}$ and in one patient with idiopathic thrombocytopenic purpura and another with autoimmune thrombocytopenia receiving high dose intravenous $\operatorname{Ig}(2 \mathrm{~g} / \mathrm{kg})$, natural killer activity decreased in correlation with the clinical response and increased peripheral cell counts. ${ }^{39}$ No mechanism was suggested for these findings.

Even more difficult to rationalise than the early and transient rise in the platelet count is the prolonged and long term response to intravenous Ig. Again, many disputable hypotheses have been advanced, some founded on reliable experimental observations, others on mere conjecture. They include:
Decrease in platelet antibody synthesis

INCREASED SUPPRESSOR LYMPHOCYTE ACTIVITY Suppression of platelet antibody production may result from an intravenous Ig induced increase, absolute or relative, in suppressor (cytotoxic) lymphocytes, ${ }^{24041}$ or alternatively enhancement of their functional activity. ${ }^{42}$ Indeed, it has been documented that IgG inhibits pokeweed mitogeninduced $B$ cell differentiation and causes non-specific suppression of polyclonal IgG biosynthesis in vitro. ${ }^{434}$ While the decrease in platelet-associated IgG following intravenous Ig treatment has been interpreted as signifying suppression of platelet antibody production, ${ }^{1336}$ some have regarded the fall as indicating a blocking effect by intravenous Ig against the attachment of platelet antibody to platelet ${ }^{45}{ }^{46}$ or even simply as representing dilution of the platelet antibody by the rising platelet count. ${ }^{47}$ Even more perplexing are reports of actual increases in platelet-associated IgG following intravenous $\mathrm{Ig}$ treatment ${ }^{48-50}$ and of platelet antibody titres in the serum having increased ${ }^{45}$ or decreased $^{10}$ with treatment. Such contradictory and baffling discrepancies may, however, merely reflect methodological differences or unreliability in the assay techniques currently used for measuring platelet antibodies.

ANTIBODY AUTOREGULATION

In 1974 Jerne proposed that antibody-producing cells may autoregulate by a network of idiotype/antiidiotype interactions. ${ }^{51}$ There is no current evidence, however, to indicate that intravenous Ig influences this autoregulatory process.

IGG2 DEFICIENCY

It has been suggested that IgG2 deficiency may have a role in the pathogenesis of idiopathic thrombocytopenic purpura and that intravenous Ig corrects this defect and by an unknown mechanism suppresses autoantibody production. ${ }^{28}$

SPECIFIC ANTI-FC $\gamma$ R ANTIBODY

The presence of specific anti-Fc $\gamma R$ antibody in intravenous Ig reduces autoantibody production (as detailed below).

\section{Increased platelet production and release}

Uchida et al found no evidence to support this hypothesis but confirmed that platelet survival is prolonged by intravenous Ig treatment. ${ }^{52}$ It is pertinent that in several studies where plasma, as a source of IgG, has been used in idiopathic thrombocytopenic purpura, the platelet response has been similar to that of intravenous Ig. ${ }^{53}$ The thrombocytopenia might not, however, have had an immune basis - at least in some such patients. Thus plasma infusions were found to maintain an adequate platelet count for several years in a patient with congenital thrombopoietin deficien$c y^{54}$ and similarly in an adult patient with thrombo- 
cytopenia. Atrah et al, although failing to elicit a clinically important increase in the platelet count with two courses of high dose intravenous Ig, repeatedly induced a sustained platelet remission with plasma infusions (unpublished observations).

\section{Suppression of natural killer cell activity}

This may be partly responsible for the immediate as well as the delayed responses to intravenous Ig.

\section{Specific anti-Fc $\gamma R$ in intravenous Ig}

This hypothesis recently postulated by Sandilands $e t$ al has not yet gained wide or adequate recognition. ${ }^{5 s}$ Because we consider it to be of paramount importance in unravelling the immunomodulatory action of intravenous Ig, a more detailed account of the mechanism and its implications follows.

The main proposition is that intravenous Ig contains an antibody which is directed against and reacts specifically with $\mathrm{Fc} \gamma \mathrm{R}$ (anti-Fc $\gamma \mathrm{R}$ ) and that its action may vary with clinical circumstance and the target cell. Thus in idiopathic thrombocytopenic purpura the $\mathrm{Fc} \gamma \mathrm{R}$ of mononuclear phagocytes blocked or modulated by the Fab portion of anti-Fc $\gamma \mathrm{R}$ have no or a reduced binding capacity for the Fc portion of the platelet antibody. Consequently, platelets and their bound antibody complex cannot be phagocytosed by the effector cells of the reticuloendothelial system. This mechanism provides insight into several different aspects of intravenous Ig treatment in idiopathic thrombocytopenic purpura and other immune disorders. Firstly, it could explain as indicated above the immediate and transient effect of intravenous Ig. Secondly, the "blocked" Fc $\gamma \mathrm{R}$ may be internalised as happens when it reacts with immune complexes, resulting in loss or modulation of target cell reactivity be it phagocytic, suppressor, helper or natural killer. It may therefore be the basis of the less common but sustained effect of intravenous Ig in idiopathic thrombocytopenic purpura through either reduced antibody production or decreased phagocytic activity of the reticuloendothelial system, or both. Thirdly, as the $\mathrm{Fab}$ (and not the $\mathrm{Fc}$ ) portion of anti-Fc $\gamma \mathrm{R}$ is the key reactant with $F c \gamma R$, unmodified as well as modified intravenous Ig can exert a therapeutic effect with the former being more effective because of the larger molecule exerting greater steric resistance for the Fc portion of other IgG molecules, including platelet antibody from displacing the Fab portion of the anti-Fc $\gamma$ R. Fourthly, it may account for the decrease in lymphocytes ${ }^{24}$ and reduced natural killer cell activity ${ }^{39}$ accompanying intravenous Ig treatment because these cells bear $F c \gamma R^{.56}$ The proposed mechanism gains additional support from the clinical demonstration that infusion of a murine-derived monoclonal anti-Fc $\gamma \mathbf{R}$ is capable of reproducing all the in vivo and in vitro effects of intravenous Ig. $^{57}$

Because anti-D has been shown to be effective in idiopathic thrombocytopenic purpura ${ }^{5859}$ it has been suggested that the success of intravenous Ig may be related to its anti-D content. ${ }^{60}$ On the other hand, another study using a different anti-D preparation and at higher doses, failed to elicit a clinically important platelet response in idiopathic thrombocytopenic purpura. ${ }^{61}$ From these disparate findings, we conclude that the active therapeutic agent may not be anti-D itself but some other constituent and venture to suggest that this is most likely to be anti-Fc $\gamma R$ which is present in both anti- $\mathrm{D}^{62}$ and intravenous $\mathrm{Ig}^{63}$ preparations.

The plausibility of this $\mathrm{Fc} \gamma \mathrm{R}$ blockade is further promoted by some recent findings in aplastic anaemia where remission has been achieved by the use of intravenous Ig. ${ }^{64}$ There, the therapeutic effect has been attributed to a substantial reduction in the number of lymphocytes belonging to an $\mathrm{Fc} \gamma \mathrm{R}$ bearing subset known to suppress haemopoiesis in patients with aplastic anaemia ${ }^{65}$ Short of bone marrow transplantation, the most effective agents in the treatment of aplastic anaemia are anti-lymphocyte globulin (ALG) or anti-thymocyte globulin (ATG), although their mode of action remains undefined. ${ }^{6667}$ Recently, however, anti-Fc $\gamma \mathbf{R}$ antibody has been detected in ALG and ATG available from three different manufacturers. ${ }^{68}$ Based on this and other evidence it has been proposed that in idiopathic thrombocytopenic purpura and aplastic anaemia the beneficial responses induced by ALG, ATG, and intravenous Ig are related to the presence of a common therapeutic principle. The recent report of the successful use of anti-D in aplastic anaemia ${ }^{69}$ supports our contention that antiFc $\gamma R$ is the active ingredient shared by intravenous $\mathrm{Ig}$, ALG, ATG and Anti-D. Additional confirmation may be derived from assessing the clinical response of monoclonal anti-Fc $\gamma \mathbf{R}$ in aplastic anaemia or its ex vivo influence on marrow culture. It is also relevant to note that increased amounts of $F c \gamma R$ are present on thymocytes in myasthenia gravis, ${ }^{70}$ a condition which responds favourably to intravenous $\mathrm{Ig}^{71}$ and that in pure red cell aplasia, an immunologically mediated disorder commonly associated with thymoma, intravenous Ig has again achieved satisfactory responses. ${ }^{72}$

\section{THERA PEUTIC IMPLICATIONS}

Fcy receptor is a non-specific marker widely distributed on granulocytes, monocytes, and lymphocyte populations and also found free in plasma. ${ }^{737}$ While anti-Fc $\gamma \mathrm{R}$ antibody develops from exposure to alloantigens (such as blood and blood products, in homosexual men and during pregnancy), ${ }^{75}$ it also seems to be a normal component of the immune network, ${ }^{63}$ with a role in the down-regulation of immune responses. As intravenous Ig is prepared from pools of donor plasma 
the anti-Fc $\gamma \mathbf{R}$ antibody content probably varies widely between different immunoglobulin products and batches. Furthermore, it is recognised that lymphocytes from individual patients respond differently to material from the same batch of any particular preparation, perhaps because of individual variation in the $F c \gamma R$ epitopes and the anti-epitopes of the anti-Fc $\gamma$ R; hence "matching" patients with batches of intravenous Ig has been suggested to establish the most appropriate reagent for each patient before treatment. ${ }^{55}$ These observations may explain the extremely variable response of patients to intravenous Ig, ALG, ATG, or Anti-D in the treatment of idiopathic thrombocytopenic purpura, aplastic anaemia, or other immune disorders where currently the selection of antibody batch is entirely empirical.

If anti-Fc $\gamma \mathbf{R}$ is the active ingredient in intravenous $\mathrm{Ig}$, it would be wasteful to continue using a crude and expensive preparation such as intravenous Ig in large doses for routine treatment; a new product (perhaps prepared from the plasma of pregnant women or deliberately immunised volunteers or modified monoclonal antibody) containing a "blend" of anti-Fc $\gamma$ R concentrates which could be used at smaller doses and lower cost would be preferred to conventional high dose intravenous Ig. The substitution of intravenous Ig by anti-D in the treatment of autoimmune disorders is to be discouraged because anti-D is a scarce human resource primarily intended for the prevention of Rhesus alloimmunisation. ${ }^{76}$ Furthermore, the mechanism of action of anti-D itself is uncertain. ${ }^{77}$ Although supportive evidence is awaited, anti-D may prevent rhesus alloimmunisation because of its anti$\mathbf{F} c \gamma \mathbf{R}$ content. This hypothesis could be verified by comparing the ability of a standard anti-D preparation from which anti-Fc $\gamma R$ has been removed for monoclonal anti-D and anti-Fc $\gamma \mathrm{R}$ which contains no anti-D to prevent alloimmunisation in rhesus $D$ negative male volunteers injected with $D$-positive cells. Anti-D remains in short supply because only donations with a high anti-D content are accepted for its preparation. If the anti-D content is shown to be therapeutically irrelevant, future interest will centre on anti-Fc $\gamma \mathbf{R}$ activity, and plasmas with high concentrations may be more readily available.

As intravenous Ig treatment is immunosuppressive it is therefore prudent to exercise caution in its administration to immunocompromised or neutropenic patients ${ }^{78}$ where the resultant reduction of Fc $\gamma R$ function may predispose to fulminant infection. While intravenous Ig does not induce generalised phagocytic blockade and is well tolerated by non-immune compromised patients, ${ }^{79}$ the effect of its long term administration in high doses to healthy subjects is not known, particularly with regard to natural killer cell activity and immunosurveillance. Furthermore, it is theor- etically possible that it may either induce immune complex disease if $\mathbf{F c} \gamma \mathbf{R}$-anti-Fc $\gamma \mathbf{R}$ complexes are deposited in tissues and organs, or amyloidosis from accumulation of the degradation products of massive quantities administered over several years. Further research is required to provide definitive solutions to those novel challenges and problems.

Finally, despite the considerable volume of evidence supporting our hypothesis embodying Fc $\gamma \mathrm{R}$ blockade, we accept that conclusive proof awaits further elucidation of several of its essential aspects. These include the mode of action of anti-Fc $\gamma \mathbf{R}$ on modifying cellular activity and the mechanism of the lymphopenia; the association between clinical response and the changes in Fc $\gamma \mathrm{R}$-bearing lymphocytes; which of the three known types of $F c \gamma R^{80}$ forms the target for the anti$F c \gamma R$ and the relation of $F c \gamma R$, a functional marker, to the currently applied cluster differentiation system of lymphocyte subset typing.

\section{References}

1 Kinkelstein MS, Uhr JW. Specific inhibition of antibody function by passively administered $19 \mathrm{~S}$ and $7 \mathrm{~S}$ antibody. Science 1964;146:67-70.

2 Riggio RR, Cheigh JS, Stenzel KH, et al. Use of gamma globulin as an immunosuppressive agent. $N Y$ State J Med 1980;80: 1561-3.

3 Berglund G. Plasma transfusion treatment of six children with idiopathic thrombocytopenia purpura. Acta Paediatr Scand 1962;51:523-8.

4 Reiquam CW, Prosper JC. Fresh plasma transfusions in the treatment of acute thrombocytopenic purpura. $J$ Paediatr 1966;68:880-4.

5 Imbach P, Barandun S, Baumgartner C, et al.High dose intravenous gammaglobulin therapy of refractory, in particular idiopathic thrombocytopenia in childhood. Helv Paediatr Acta $1981 ; 36: 81-6$.

6 Imbach P, Barandun S, D’Apuzzo V, et al. High dose intravenous gammaglobulin for idiopathic thrombocytopenia purpura in childhood. Lancet 1981;i:1228-31.

7 Bussel JB, Schulman I, Hilgartner MW, Barandun S. Intravenous use of gammaglobulin in the treatment of chronic immune thrombocytopenia as a means to defer splenectomy. $J$ Paediatr 1983;103:651-4.

8 Schmidt RE, Budde U, Schafer G, Stroefman I. High dose intravenous gammaglobulin for idiopathic thrombocytopenic purpura. Lancet 1981;ii:475-6.

9 Fehr J, Hofmann V, Kappeler U. Transient reversal of thrombocytopenia in idiopathic thrombocytopenia by high dose intravenous gammaglobulin. N Engl J Med 1982;306:1254-8.

10 Newland AC, Treleaven JG, Minchinton RM, Waters AH. High dose intravenous IgG in adults with autoimmune thrombocytopenia. Lancet 1983 ; i:84-7.

11 Atrah HI, Crawford RJ, Gabra GS, Mitchell R. Intravenous immunoglobulin therapy for idiopathic thrombocytopenic purpura. Scot Med J 1986;31:231-3.

12 Bussel JB, Pham LC. Intravenous treatment with gammaglobulin in adults with immune thrombocytopenic purpura. Review of the literature. Vox Sang 1987;52:206-11.

13 Stiehm ER, moderator. Intravenous immunoglobulins as therapeutic agents. Ann Intern Med 1987;107:367-82.

14 Proceedings of a Symposium: Innovative uses of intravenous immunoglobulins in Clinical Hematology. Am $\mathrm{J}$ Med 1987;83:(suppl 4A): 1-59. 
15 Bussel JB, Kimberly RP, Inman RD, et al. Intravenous gammaglobulin treatment of chronic idiopathic thrombocytopenic purpura. Blood 1983;62:480-6.

16 Segal DM, Dower SK, Titus JA. The role of non-immune IgG in controlling IgG-mediated effector functions. Mol Immunol 1983;20:1177-89.

17 Kimberly RP, Salmon JE, Bussel JB, Crow MK, Hilgartner MW. Modulation of mononuclear phagocyte function by intravenous $\gamma$-globulin. J Immunol 1984;132:745-50.

18 Kurlander RJ. Reversible and irreversible loss of Fc receptor function of human monocytes as a consequence of interaction with immunoglobulin G. J Clin Invest 1980;66:773-81.

19 Romer J, Morgenthaler JJ, Scherz R, Skavril F. Characterization of various immunoglobulin preparations for intravenous application. Vox Sang 1982;42:62-73.

20 Augener W, Friedman B, Brittinger G. Are aggregates of IgG the effective part of high-dose immunoglobulin therapy in adult idiopathic thrombocytopenic purpura (ITP)? Blut 1985;50: 249-52.

21 Bussel JB, Hilgartner MW. Annotation: The use and mechanism of action of intravenous immunoglobulin in the treatment of immune haematologic disease. Br J Haematol 1984;56:1-7.

22 Salama A, Mueller-Eckhardt C, Kiefel V. Effect of intravenous immunoglobulin in immune thrombocytopenia. Lancet 1983;ii:193-5.

23 Newland AC. The use of intravenous IgG in immune cytopeniasA review. Apheresis Bulletin 1984;2:13-23.

24 Dammacco F, Iodice G, Campobasso N. Treatment of adult patients with idiopathic thrombocytopenic purpura with intravenous immunoglobulin: effects on circulating $T$ cell subsets and PWM-induced antibody synthesis in vitro. $\mathrm{Br} J$ Haematol 1986;62:125-35.

25 Saleh MN, Court WS, LoBuglio AF. In vitro effects of gammaglobulin (IgG) on human monocyte Fc receptor function. Am J Hematol 1986;23:197-207.

26 Atrah HI, Crawford RJ. Blood group and response to immunoglobulin in immune thrombocytopenia. Lancet 1984;ii:810.

27 Macey MG, Sangster JM, Newland AC. Blood group and response to high dose IgG. Lancet 1985 ; $1: 1445$.

28 Bussel JB. Treatment with intravenous gammaglobulin: use in chronic idiopathic thrombocytopenic purpura to avoid splenectomy; and mechanism of action. Intravenous immunoglobulins. The Royal Society of Medicine International Congress and Symposium Series 1985;84:83-9.

29 Budde U, Auch D, Niese D, Schäfer G, Reske S, Schmidt R. Reticuloendothelial system Fc-receptor function in patients with immune thrombocytopenia after treatment with high dose intravenous immunoglobulin. Scand J Haematol 1986;37: 125-9.

30 Solal-Celigny P, Bernard JF, Herrera A, Boivin P. Treatment of adult autoimmune thrombocytopenic purpura with high-dose intravenous plasmin-cleaved gammaglobulins. Scand $J$ Haematol 1983;31:39-44.

31 Emilia G, Sacchi S, Torelli G, Selleri L, Torelli U. Low-dose intravenous pepsin-treated gammaglobulin for idiopathic thrombocytopenic purpura in adults. $\mathrm{Br} J$ Haematol 1984;58:761-2.

32 Tovo PA, Miniero R, Fiandino G, Saracco P, Messina M. Fcdepleted versus intact intravenous immunoglobulin in chronic ITP. J Pediatr 1984;105:676-7.

33 Sultan Y, Kazatchkine MD, Maisonneuve P, Nydegger UE. Antiidiotype suppression of autoantibodies to Factor VIII (Antihaemophilic Factor) by high-dose intravenous gammaglobulin. Lancet 1984;ii:765-8.

34 Imbach P, Jungi TW. Possible mechanisms of intravenous immunoglobulin treatment in childhood idiopathic thrombocytopenia purpura. Blut 1983;46:117-24.

35 Gross B, Haessig A, Luescher EF, Nydegger UE. Monomeric IgG preparations for intravenous use inhibit platelet stimulation by polymeric IgG. Br J Haematol 1983;53:289-99.
36 Kurata Y, Tsubakio T, Yonezawa T, Tarui S. High-dose gammaglobulin therapy for idiopathic thrombocytopenic purpura. Acta Haematol 1983;69:391-7.

37 Blanchette V, Hogan V, Hsu E, Luke B, Rock G. Mechanism of action of high dose intravenous (IV) gammaglobulin therapy in childhood immune thrombocytopenia purpura (ITP). Paediatr Res 1983;17:229A.

38 Minchinton RM, McGrath K. Binding and antibody blocking effects of intravenous IgG preparation on peripheral blood cells. Clin Lab Haematol 1987;9:49-58.

39 Engelhard D, Waner JL, Kapoor N, Good RA. Effect of intravenous immune globulin on natural killer cell activity: possible association with autoimmune neutropenia and idiopathic thrombocytopenia. J Pediatrics 1986;108:77-81.

40 Kawada K, Terasaki PI. Evidence for immunosuppression by high dose gammaglobulin. Exp Haematol 1987;15:133-6.

41 Tsubako T, Kurata Y, Katagiri S, et al. Alteration of T cell subsets and immunoglobulin synthesis in vitro during high dose $\gamma$ globulin in patients with idiopathic thrombocytopenic purpura. Clin Exp Immunol 1983;53:697-702.

42 Delfraissy JF, Tchernia G, Laurian Y, Wallon C, Galanaud P. Suppressor cell function after intravenous gammaglobulin treatment in adult chronic idiopathic thrombocytopenic purpura. Br J Haematol 1985;60:315-22.

43 Durandy A, Fischer A, Criscelli C. Dysfunctions of pokeweed mitogen-stimulated $\mathrm{T}$ and $\mathrm{B}$ lymphocyte responses induced by gammaglobulin therapy. $J$ Clin Invest 1981;67:867-77.

44 Stohl W. Cellular mechanisms in the in vitro inhibition of pokeweed mitogen-induced B cell differentiation by immunoglobulin for intravenous use. $J$ Immunol 1986;136:4407-13.

45 Winiarski J, Kreuger A, Ejderhamn J, Holm G. High dose intravenous IgG reduces platelet associated immunoglobulin and complement in idiopathic thrombocytopenic purpura. Scand J Haematol 1983;31:342-8.

46 Ball S, Zuiable A, Roter BLT, Hegde UM. Changes in platelet immunoprotein levels during therapy in adult immune thrombocytopenia. Br J Haematol 1985;60:631-3.

47 Schmidt RE, Budde U, Broschen-Zywietz C, Schafer G, MullerEckhardt $C$. High dose gammaglobulin therapy in adults with idiopathic thrombocytopenic purpura [ITP) clinical effects. Blut 1984;48:19-25.

48 Schmidt B, Forster J. Increased platelet-associated IgG in child on high-dose gammaglobulin for idiopathic thrombocytopenic purpura. Lancet 1982;ii:39-40.

49 Bierling P, Farcet JP, Duedari N, Rochant H. Increased plateletassociated IgG in patient on high-dose gammaglobulin for autoimmune thrombocytopenic purpura. Lancet 1982;ii:388.

50 Morgenstern GR, Measday B, Hegde UM. Autoimmune thrombocytopenia in pregnancy: new approach to management. $\mathrm{Br}$ Med $J$ 1983;287:584.

51 Jerne NK. Towards a network theory of the immune system. Ann Immunol 1974;125C:373-89.

52 Uchida T, Yui T, Umezu H, Kariyoni S. Prolongation of platelet survival in idiopathic thrombocytopenic purpura by high-dose intravenous gamma globulin. Thromb Haemostas 1984;51:65-6.

53 Lehoczky D, Kelemen E. Gammaglobulin for idiopathic thrombocytopenic purpura. N Engl J Med 1982;307:1150-1.

54 Hardisty RM. Disorders of platelets. In: Hoffbrand AV, Lewis SM, eds. Postgraduate haematology. 2nd ed. London: Heineman, 1981:647.

55 Sandilands GP, Atrah HI, Templeton G, et al. In vivo and in vitro blocking of human lymphocyte Fc $\gamma$-receptors by intravenous gammaglobulin. J Clin Lab Immunol 1987;23:109-115.

56 Kay HD, Bonnard GD, West WH, Herberman RB. A functional comparison of human Fc-receptor-bearing lymphocytes active in natural cytotoxicity and antibody-dependent cellular cytotoxicity. J Immunol 1977;118:2058-66.

57 Clarkson SB, Bussel JB, Kimberly RP, Valinsky JE, Nachman RL, Unkeless JC. Treatment of refractory immune thrombocytopenic purpura with an anti-Fc $\gamma$-receptor antibody. $N$ 
Engl J Med 1986;314:1236-9.

58 Salama A, Kiefel V, Amberg R, Mueller-Eckhardt C. Treatment of autoimmune thrombocytopenic purpura with rhesus antibodies (anti-Rho [D]). Blut 1984;49:29-35.

59 Baglin TP, Smith MP, Boughton BJ. Rapid and complete response of immune thrombocytopenic purpura to a single injection of rhesus anti-D immunoglobulin. Lancet 1986;i:1329-30.

60 Lucas GS, Jobbin K, Bloom AL. Intravenous immunoglobulin and blood group antibodies. Lancet 1987;ii:742.

61 Atrah HI, Templeton JG, Crawford RJ, Gabra GS, Mitchell R. Passive haemagglutination inhibition for quantitation of red cell associated IgG. J Clin Pathol 1987;40:494-9.

62 Petri IB, Lorincz A, Berek I. Detection of Fc-receptor-blocking antibodies in anti- $\mathrm{Rh}(\mathrm{D})$ hyperimmune gammaglobulin. Lancet 1984;ii:1478-9.

63 Cocker JE, Templeton G, Peel MG, Crawford RJ, Crichton WB, Sandilands GP. Lymphocyte Fcy-receptor blocking antibodies in intravenous gammaglobulin preparations. J Clin Lab Immunol 1987;22:85-90.

64 Atrah HI, Crawford RJ, Gabra GS, et al. Modulation of suppressor $\mathrm{T}$ cells for the treatment of aplastic anaemia. Lancet 1985;ii:339-40.

65 Bacigalupo A, Podesta M, Mingari MC, Moretta L, Van Lint MT, Marmont A. Immune suppression of haemopoiesis in aplastic anaemia: activity of $\mathrm{T} \gamma$ lymphocytes. J Immunol 1980;125: 1449-53.

66 Thomas ED, Storb R. Acquired severe aplastic anaemia: progress and perplexity. Blood 1984;64:325-8.

67 Champlin R, Winston H, Gale RP. Antithymocyte globulin treatment in patients with aplastic anaemia. $N$ Engl $J$ Med 1983;308:113-8.

68 Atrah HI, Sandilands GP. A proposed mechanism of action of ALG and ATG in acquired severe aplastic anaemia. J Clin Lab Immunol 1988;25:59-62.

69 Rewald E. Repeated low doses of anti-rhesus gammaglobulin in aplastic anaemia. Lancet 1987;ii:795.

70 Gilhus NE, Matre R. Fc $\gamma$ receptors and HLA-DR antigens on thymus cells in myasthenia gravis. $J$ Neuroimmunol 1986;10:271-8.

71 Arsura EL, Bick A, Brunner NG, Namba T, Grob D. High dose intravenous immunoglobulin in the treatment of myasthenia gravis. Arch Intern Med 1986;146:1365-8.

72 Claurel JP, Vainchenker N, Herrera A, et al. Treatment of pure red cell aplasia by high dose intravenous immunoglobulins. $\mathrm{Br} J$ Haematol 1984;55:380-2.

73 Cohen L, Sharp S, Kulczycki A. Human monocytes, B lymphocytes and non-B lymphocytes each have structurally unique $\mathrm{Fc} \gamma$ receptors. J Immunol 1983;131:378-83.

74 Khayat D, Geffrier C, Serena Yoon, et al. Soluble circulating Fcy receptors in human sera. $J$ Immunol Methods 1987;100:235-41.

75 Forwell M, Gray KG, MacSween RNM, et al. Immunosuppression following alloantigen exposure: a role for lymphocyte Fcyreceptor blocking antibodies? J Clin Lab Immunol 1986; 19:53-7.

76 Contreras M, Mollison PL. Anti-Rh(D) immunoglobulin for immune thrombocytopenic purpura. Lancet 1986;ii:49.

77 Pollack W. Mechanisms of $\mathrm{Rh}$ immune suppression by $\mathrm{Rh}$ immune globulin. In: Garratty G, ed. Hemolytic disease of the newborn. Arlington, Virgina: American Association of Blood Banks, 1984:53-66.

78 Cross AS, Alving BM, Sadoff JC, Baldwin P, Terebelo H, Tang D. Intravenous immune globulin: a cautionary note. Lancet 11984;i:912.

79 Salmon JE, Kapur S, Kimberly RP. Gammaglobulin for intravenous use induces an $\mathrm{Fc} \gamma$ receptor-specific decrement in phagocytosis by blood monocytes. Clin Immunol Immunopathol 1987;43:23-33.

80 Vaughn M, Taylor M, Mohanakumar T. Characterization of human IgG Fc receptors. J Immunol 1985;135:4059-65.

Requests for reprints to: Dr H I Atrah, Department of Haematology, Aberdeen Royal Infirmary, Foresterhill, Aberdeen AB9 22D, Scotland. 